[Agr. Biol. Chem., Vol. 33, No. 3, p. 409 413, 1969]

\title{
Leaf Alcohol
}

\section{Part XVIII. Condensation of Leaf Aldehyde by Means of Diethylamine}

\author{
By Tadahiko Kajiwara, Akikazu Hatanaka, Yuzo Inouye \\ and Minoru OHNo \\ Institute for Chemical Research, Kyoto University \\ $U j i$, Kyoto, Japan \\ Received September 4, 1968
}

\begin{abstract}
The diethylamine-catalyzed aldol condensation of $E$-2-hexenal yielded a mixture of 2-E,4-E,6-E- (IV-a) and 2-E,4-Z,6-E-4-ethyldeca-2,4,6-triene-1-al (IV-b). Structual and geometrical elucidation of both alcohols were made by means of spectral evidence as well as by the catalytic hydrogenation leading to the same 4-ethyldecanol (VI). The "b-peak substance" detected in the leaf alcohol reaction products was proved to be identical with 4-ethyldecanol (VI). The treatment of the trienal containing the central $Z$-double bond with sodium under the leaf alcohol reaction condition failed to afford ethyl-propyl-benzyl alcohol, but gave 4-ethyldecanol (VI). This result safely excludes the operation of the previously suspected valence tautomerism (Cope rearrangement) in the leaf alcohol reaction, and accounts for the pathway of the formation of (VI).
\end{abstract}

In the previous paper, ${ }^{1-a}$ the mechanism of leaf alcohol reaction has been proposed on the basis of a model reaction with crotonaldehyde (I-a) which on stepwise treatments with diethylamine and metallic sodium gave the leaf alcohol reaction product, o-methyl-benzyl alcohol (III-a), via 2-methyl cyclohexadiene aldehyde (II-a).

$$
\begin{array}{llll} 
& & \\
\mathrm{CH}_{2} \mathrm{R} & \mathrm{R}: & \mathrm{H} & \text { (II-a) } \\
\mathrm{H} & \mathrm{R}: & \mathrm{C}_{2} \mathrm{H}_{5} & \text { (II-b) } \\
\mathrm{H} & & &
\end{array}
$$

This was further confirmed by the same reaction sequence with leaf aldehyde as such (Ib) which on treatment with ethanolic sodium hydroxide, instead of diethylamine, yielded a

1) a) M. Ohno, Y. Inouye, A. Hatanaka and $T$. Kajiwara, Bull. Inst. Kyoto Univ., 43, 231 (1963). b) A. Hatanaka, T. Kajiwara und M. Ohno, Agr. Biol. Chem., 31, 964 (1967). cyclic intermediate, 2-propyl-5-ethyl-cyclohexadiene-aldehyde (II-b), eventually leading to 2-propyl-5-ethyl-benzyl alcohol (III-b). ${ }^{1-b)}$

In the case of the previous model reaction with crotonaldehyde, the first Michael-Aldol condensation of crotonaldehyde was easily effected by diethylamine to afford the cyclodienealdehyde (II-a), whereas the same treatment of leaf aldehyde $(E \text {-2-hexenal })^{21}$ with diethylamine gave acyclic compounds (IV), in contrast to expectation.

In the present paper, the elucidation of structures of the compounds (IV) and the mechanism of formation thereof are described.

$E$-2-Hexenal when warmed with diethylamine yielded a neutral fraction distilling over

2) J. E. Blackwood, J. Am. Chem. Soc., 90, 509 (1968). For specifying the geometry of polysubstituted ethylenic linkages, the novel $Z, E$-system based on the sequence rule and being currently adopted in the Chemical Abstract was preferred here to the conventional cis, trans-notation. 
the range of $72 \sim 8^{\circ} \mathrm{C} / 3 \mathrm{~mm}$, which consisted of two components as indicated by two peaks on vpc-analysis. A clear-cut separation of the fraction into two components (IV-a and IV-b) was effected by means of preparative vpc and the IR-spectrum of each component suggested the presence of double bonds and aldehyde group. Consistently, both components gave the corresponding 2,4-dinitrophenylhydrazone melting at $132 \sim 4^{\circ} \mathrm{C}\left(\mathrm{IV}^{\prime}\right.$-a) and $145^{\circ} \mathrm{C}\left(\mathrm{IV}^{\prime}\right.$-b) respectively and the elemental analyses of both derivatives showed that both parent aldehydes are isomeric to each other and have the same constitution, $\mathrm{C}_{12} \mathrm{H}_{18} \mathrm{O}$, involving one aldehyde group and three double bonds. The $U V$-spectra of $\left(I V^{\prime}-a\right)$ and $\left(I V^{\prime}-b\right)$ equally showed the absorption maxima at $402 \mathrm{~m} \mu$ which strongly supported the conjugated triene aldehyde structure of both compounds, in conformity to the IR-analysis. These data when combined with the hydrogenation of (IVa) and (IV-b) to give the same and identical saturated aliphatic alcohol, 4-ethyldecanol (VI) (vide infra) enables one to deduce that both aldehydes are a substituted triene aldehyde of the same carbon skeleton and differ only in the geometry of double bond. In view of the accumulated knowledge of basecatalyzed aldol condensation of aldehyde, in particular of $\alpha, \beta$-unsaturated aliphatic aldehydes which have been prosecuted in this series of papers, it is most likely that they are geometrical isomers of 4-ethyl-deca-2,4,6triene-1-al which resulted from the aldolization and dehydration of two molecules of leaf aldehyde. Accepting this as a reasonable deduction, the geometrical isomerism between (IV-a) and (IV-b) should have originated in the central 4-double bond being newly formed in the $\mathrm{C}_{12}$-system, the other two double bonds at 2- and 6-positions in both condensates inherently possessing the $E$-configuration of the parent leaf aldehyde.

The change in geometrical configuration in polyene systems is sensitively reflected in intensity of UV-absorption and the difference

$$
\begin{aligned}
& \stackrel{\mathrm{C}_{3} \mathrm{H}_{7}}{\mathrm{H}}>\underset{\mathrm{C}=\mathrm{C}}{\mathrm{C}}>\mathrm{C}=\underset{\mathrm{H}}{\mathrm{C}}>\stackrel{\mathrm{C}=\mathrm{C}}{\mathrm{C}_{2} \mathrm{H}_{5}}>\mathrm{CHO} \\
& \underset{\mathrm{H}_{7}}{\mathrm{C}_{3} \mathrm{H}_{7}}>\underset{\mathrm{C}=}{\mathrm{C}}>\underset{\mathrm{C}=\mathrm{C}}{\mathrm{C}}>\underset{\mathrm{C}_{2} \mathrm{H}_{5}}{\mathrm{C}=\mathrm{C}}>>\underset{\mathrm{H}}{\mathrm{CHO}}
\end{aligned}
$$

in intensity was actually observed with the isomeric dinitrophenylhydrazones (IV'-a; $\varepsilon$ $\left.2.82 \times 10^{4}\right)$ and $\left(I V^{\prime}-b ; \varepsilon 2.68 \times 10^{4}\right)$. Based on this finding, it may be safely concluded that (IV-a) with the greater intensity is the all- $E$ isomer and the other (IV-b) with the smaller intensity is of the remaining possibility $E-Z-E$ configuration. In accordance, the IR-spectra of these derivatives showed the presence of $E$-trisubstituted ethylene group ( ${ }_{\nu} \mathrm{CH} 834 \mathrm{~cm}^{-1}$ ) in $\left(I V^{\prime}-a\right)$ and $Z$-trisubstituted ethylene band ( $2 \mathrm{CH} 832,850 \mathrm{~cm}^{-1}$ ) in (IV'-b). The scale model inspection revealed that the steric hindrance is comparable in both geometrical isomers, which was actually reflected in the rather anomalously small difference in intensity $(\Delta \varepsilon, 1500)$ as well as in the isomer ratio of the products $(55: 45)$ found by vpc-analysis. Both aldehydes (IV-a, IV-b), when reduced with lithium aluminum hydride followed by catalytic hydrogenation, yielded the same and identical aliphatic alcohol, 4-ethyldecanol (VI), thereby establishing the above-mentioned carbon skeleton.

Since 4-ethyldecanol (VI) was unknown in literature, this compound was synthesized in the present work by the following scheme starting from diethyl malonate: the structure is evidenced by unequivocal sequences of chemical transformation.

Of the two geometrical isomers separated, the aldehyde (IV-b) with Z-central double bond may, in principle, be capable of cyclization. In connection with the earlier assumption that the aromatization in the leaf alcohol reaction may proceed through aldol condensation and subsequent Cope rearrangement of the first formed triene aldehyde intermediate, it seems of particular interest to submit this compound to the leaf alcohol reaction conditions. Attempted cyclization 
and/or aromatization of (IV-b) by treatment with metallic sodium under the leaf alcohol reaction conditions was doomed to failure since the reaction product isolated here was 4-ethyldecanol (VI) and neither cyclohexadiene intermediate nor substituted benzyl alcohol was formed at all. Consequently, the possibility of operation of aldol condensation followed by Cope rearrangement can be safely excluded, which renewedly furnishes convincing evidence for the proposed mechanism of leaf alcohol reaction.

Fortuitously enough, 4-ethyldecanol obtained by the metallic sodium treatment of $(\mathrm{V})$ or by the exhaustive hydrogenation of both $(I V-a)$ leaf aldehyde to give firstly isomeric 4-ethyldeca-2,4,6-trienealdehyde, (IV-a) and/or (IV-b), followed by the exhaustive reduction of the intermediate with metallic sodium.

The structural elucidation of the diethylamine-catalyzed condensation products of leaf alcohol and their reduction to 4-ethyldecanol as well as the identification of the b-peak substance as 4-ethyldecanol constitute the resolution of the sole pending problem in leaf alcohol reaction i.e. it implies that the leaf alcohol reaction has now been completely understood in structure and mechanism of formation of all the reaction products hitherto isolated.
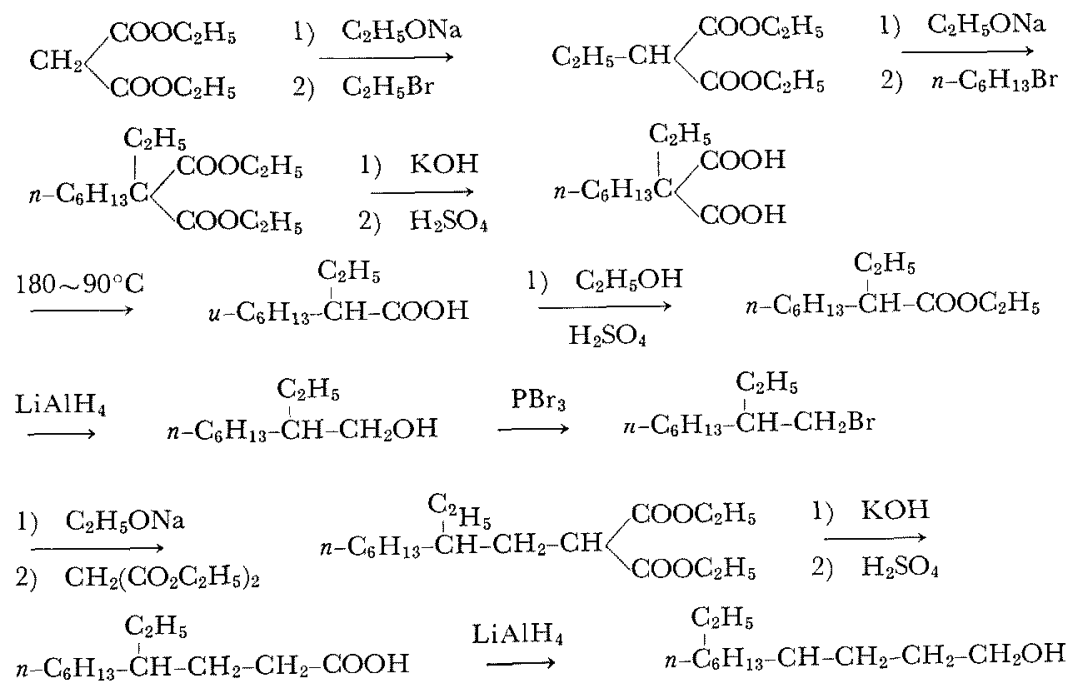

and (IV-b), was found to be identical with one of the by-products in leaf alcohol reaction which was provisionally designated as "b-peak substance" of unknown structure in the earlier work. ${ }^{4 !}$ It then follows that the formation of 4-ethyldecanol as a by-product in leaf alcohol reaction may be interpreted as the consequence of base-catalyzed aldolization of

3) M. Ohno, Y. Inouye, A. Hatanaka, and T. Kajiwara, Bull. Inst. Kyoto Univ., 43, 236 (1965).

\section{EXPERIMENTAL}

Condensation of 2-E-hexen-1-al (I-b) using diethylamine. Diethylamine $(1.3 \mathrm{~g}, 0.018 \mathrm{~mole})$ was added to $E$ hexenal (I-b) $(17.60 \mathrm{~g}, 0.180$ mole) during $1 \mathrm{hr}$ with stirring under nitrogen atmosphere and the temperature was kept at $65^{\circ} \mathrm{C}$. After addition was completed, the reaction mixture was warmed at $75^{\circ} \mathrm{C}$ for $1 \mathrm{hr}$ and distilled in vacuo to yield the following

4) A. Hatanaka and M. Ohno, Agr. Biol. Chem., 28, $910(1964)$. 
fractions; (1) $4 \mathrm{~g}$, bp $73 \sim 6^{\circ} \mathrm{C} / 3 \mathrm{~mm}$, crude aldehyde (IV); (2) $1.3 \mathrm{~g}$, bp $78 \sim 104^{\circ} \mathrm{C} / 3 \mathrm{~mm}$; (3) residue.

Isolation of aldehydes $(I V-a)$ and $(I V-b)$ by preparative $v p c$. The compounds (IV-a) and (IV-b) were isolated by preparative vpc (Barber Colman).

Retention time: (IV-a), $12.5 \mathrm{~min}$ (IV-b), $13.5 \mathrm{~min}$ Aerograph: A-700, Detector; TCD

Column: $\quad 5 \%$ Carbowax $20 \mathrm{M}, 150^{\circ} \mathrm{C}$ Detector; $250^{\circ} \mathrm{C}$

Injector: $250^{\circ} \mathrm{C}$, Collector $270^{\circ} \mathrm{C}$

Gas flows: $200 \mathrm{ml} / \mathrm{min}$

Sample size: $\quad 2.5 \mu \mathrm{l}$

2.4.-Dinitrophenyl hydrazone of $\left(\mathrm{IV}^{\prime}-\mathrm{a}\right), \mathrm{mp} 132 \sim 4^{\circ} \mathrm{C}$ : Anal. Found: C, 60.43; H, 6.19; N, 15.22. Calcd. for $\mathrm{C}_{18} \mathrm{H}_{22} \mathrm{~N}_{4} \mathrm{O}_{4} \mathrm{C}, 60.32 ; \mathrm{H}, 6.19 ; \mathrm{N}, 15.63 \%$ (IV'-b) $\mathrm{mp} 145^{\circ} \mathrm{C}$ : Anal. Found: C, 59.96; H, 6.11; N, 15.68 . Calcd. for $\mathrm{C}_{18} \mathrm{H}_{22} \mathrm{~N}_{4} \mathrm{O}_{4} \mathrm{C}, 60.32 ; \mathrm{H}, 6.19 ; \mathrm{N}, 15.63 \%$.

Treatment of (IV) with metallic sodium:-A mixture of (IV) $(8 \mathrm{~g})$ and sodium $(4.6 \mathrm{~g}, 0.1$ atom) in $p$ xylene was refuxed for $3 \mathrm{hr}$. The reaction mixture was poured into water and extracted with ether. The extract, after drying and removal of the solvent, gave (VI), bp $130 \sim 7^{\circ} \mathrm{C} / 12 \mathrm{~mm}$, yield, $0.7 \mathrm{~g}$.

4-Ethyldecatriene alcohol (V). A solution of IV $(1.7 \mathrm{~g})$ in ether $(10 \mathrm{ml})$ was treated with lithium aluminum hydride $(0.37 \mathrm{~g})$ to give a colorless alcohol (V), bp $80 \sim 5^{\circ} \mathrm{C} / 3 \mathrm{~mm}, n_{\mathrm{D}}^{10} 1.4978$.

4-Ethyldecanol $(V I)$. A sample of the above alcohol (V) $(0.8 \mathrm{~g})$, dissolved in $50 \mathrm{ml}$ of ethyl acetate was hydrogenated in the presence of $\mathrm{PtO}_{2}(0.005 \mathrm{~g})$ until the theoretical amount of hydrogen was absorbed. After filtering the catalyst, ethyl acetate was evaporated in vacuo, leaving a mass of brown oil. Distillation of the residue gave $0.5 \mathrm{~g}$ of 4-ethyldecanol (VI), bp $130 \sim 5^{\circ} \mathrm{C} / 12 \mathrm{~mm}$. The alcohol (VI) was identical with the fraction "b-peak substance" in vpc.

Flow rate: $\quad 175 \mathrm{ml} / \mathrm{min}$, Temp: $165^{\circ} \mathrm{C}$

Column: $\quad$ P. E. G. $6000(0.6 \times 60 \mathrm{~cm})$

Retention time: Fraction $b,(\mathrm{VI}) ; 5 \mathrm{~min}$

Isolation of b-peak substance by preparative vpc. The compound was isolated by preparative vpc (Barber Colman).

Column: $\quad 5 \%$ Carbowax $20 \mathrm{M}$, Temp $170^{\circ} \mathrm{G}$

Flow rate: $200 \mathrm{ml} / \mathrm{min}$

3,5-Dinitrobenzoate from b-peak substance; $\mathrm{mp} \mathrm{22 \sim}$ $5^{\circ} \mathrm{C}$ (from ethanol). Anal. Found: C, 60.07; H, 7.63; $\mathrm{N}, 7.15$; Calcd. for $\mathrm{C}_{19} \mathrm{H}_{28} \mathrm{O}_{6} \mathrm{~N}_{2}: \mathrm{C}, 59.98 ; \mathrm{H}, 7.42$; $\mathrm{N}, 7.36 \%$.

Ethyl ethylmalonate. To a solution of sodium (4.6 g, 0.20 atom) in $75 \mathrm{ml}$ of absolute alcohol was added ethyl malonate $(33 \mathrm{~g}, 0.206$ mole) while the liquid was mechanically stirred. The mixture was heated on a steam-bath and stirred while ethyl bromide ( $25 \mathrm{~g}, 0.253 \mathrm{~mole}$ ) was added slowly. The heating was continued for one and a half hrs during which time a copious separation of sodium occurred, and the mixture became neutral to litmus. The greater part of the alcohol was distilled during continued stirring and the residue dissolved in water. The oily layer was separated and treated in the usual way. Fractionation at atmospheric pressure gave a colorless oil boiling at $105 \sim 2^{\circ} \mathrm{C} / 15 \sim 6 \mathrm{~mm}, 30 \mathrm{~g}$ $(56.3 \%), n_{\mathrm{D}}^{32} 1.4130$.

Diethyl ethyl, n-hexylmalonate. The ethyl group was introduced first for the reason that a greater difference in boiling point occurs between the monoalkylated ester and the dialkylated product, thus facilitating purification of the product. To a solution of sodium ( $7.54 \mathrm{~g}, 0.328$ atom) in $100 \mathrm{ml}$ absolute alcohol were added ethyl ethylmalonate $(61.6 \mathrm{~g}$, $0.375 \mathrm{~mole})$ and hexyl bromide $(67.1 \mathrm{~g}, 0.375 \mathrm{~mole})$. Fractionation at $7 \sim 8 \mathrm{~mm}$ gave $59 \mathrm{~g}(46.1 \%)$ of a colorless oil boiling at $135 \sim 8^{\circ} \mathrm{C}, n_{\mathrm{D}}^{32} 1.4284$, yield after the procedure described for ethyl ethylmalonate.

Ethyl, hexylmalonic acid. Saponification of the ester was effected by refluxing for $5 \mathrm{hr}$ a homogeneous mixture of $13 \mathrm{~g}$ of ester, $25 \mathrm{ml}$ of water and $50 \mathrm{ml}$ of ethyl alcohol with $10 \mathrm{~g}$ potassium hydroxide. The solvent was then evaporated and the residue was cooled and acidified with $20 \mathrm{ml}$ of conc. HCl. The free acid separated as an oil. This was extracted with ether and the ether evaporated. The crystals were then dried on a porous plate and washed with a little, petroleum ether. The product consisted of very small, colorless needles melting at $75^{\circ} \mathrm{C}$ and decomposing at about $140^{\circ} \mathrm{C}$ with evolution of carbon dioxide. Anal. Found: C, 61.01; H, 9.70. Calcd. for $\mathrm{C}_{11} \mathrm{H}_{20} \mathrm{O}_{4}$ : C, 61.11; H, 9.26\%。.

2-Ethyloctanoic acid. The distillation in Claisen flask of dicarboxylic acid under reduced pressure gave the crude 2-ethyloctanoic acid. Redistillation of the material gave colorless oil boiling at $145 \sim 50^{\circ} \mathrm{C} / 12$ 
$\mathrm{mm}, n_{\mathrm{D}}^{32} 1.4290$.

2-Ethyloctanoic acid ethyl ester. The yield of ester from 2-ethyloctanoic acid ( $43 \mathrm{~g}, 0.249 \mathrm{~mole}$ ), absolute alcohol $(115 \mathrm{~g})$, and conc. $\mathrm{H}_{2} \mathrm{SO}_{4}$ after refluxing for $22 \mathrm{hr}$, was $41 \mathrm{~g}(83.9 \%)$ of bp $105 \sim 115^{\circ} \mathrm{C} / 12 \sim 3 \mathrm{~mm}$, $n_{\mathrm{D}}^{32} 1.4202$.

2-Ethyloctyl alcohol. The lithium aluminum hydride reduction of 2-ethyloctanoic acid ethyl ester $(20 \mathrm{~g}, 0.1 \mathrm{~mole})$ gave the corresponding alcohol, 2-ethyl octyl alcohol, bp $111 \sim 5^{\circ} \mathrm{C} / 12 \mathrm{~mm}, n_{\mathrm{D}}^{32} 1.4341$, yield $13.5 \mathrm{~g}(85.5 \%)$. 3,5-Dinitrobenzoate: $\mathrm{mp} \quad 41 \sim 2^{\circ} \mathrm{C}$ (from ethanol). Anal. Found: C, 57.98; H, 6.88; N, 7.98. Calcd. for $\mathrm{C}_{17} \mathrm{H}_{24} \mathrm{~N}_{2} \mathrm{O}_{6}: \mathrm{C}, 57.94 ; \mathrm{H}, 6.87 ; \mathrm{N}$, $7.95 \%$.

2-Ethyloctyl bromide. In a flask were placed 48 per cent hydrobromic acid ( $1 \mathrm{lg}, 0.065$ mole), conc. $\mathrm{H}_{2} \mathrm{SO}_{4}(3 \mathrm{~g})$, and 2-ethyloctyl alcohol (5 g, 0.025 mole). The mixture was boiled under reflux for $6 \mathrm{hr}$. The solution was diluted with water and the bromide layer was separated, washed once with a little cold conc. sulfuric acid, then with water and finally with dil. sodium carbonate solution, after usual procedure. The product was collected at $105 \sim 9^{\circ} \mathrm{C} / 12 \mathrm{~mm}, n_{\mathrm{D}}^{32}$ 1.4538 and amounted to $4.6 \mathrm{~g}(82.4 \%)$.
Ethyl 2-ethyl-octylmalonate. To a solution of sodium $(0.92 \mathrm{~g}, 0.04$ atom) in $20 \mathrm{ml}$ of absolute alcohol was added ethyl malonate $(6.6 \mathrm{~g}, 0.04$ mole) and 2-ethyl octyl bromide $(8.8 \mathrm{~g}, 0.04$ mole): this was prepared in the same manner as just described. The yield was $6.2 \mathrm{~g}(51.5 \%)$ boiling at $158 \sim 62^{\circ} \mathrm{C} / 7 \sim 8 \mathrm{~mm}, \quad n_{\mathrm{D}}^{32}$ 1.4350 .

2-Ethyl-octylmalonic acid. This was prepared in the same manner as the compound just described, using $5.4 \mathrm{~g}$ (0.097 mole) of alcoholic potassium hydroxide (water $13.5 \mathrm{ml}$, alcohol $27 \mathrm{ml}$ ).

4-Ethyldecanoic acid. This was prepared in the same manner as the compound just described, using 2-ethyl, octylmalonic acid. The corresponding acid was $3.5 \mathrm{~g}$, bp $173 \sim 5^{\circ} \mathrm{C} / 14 \sim 5 \mathrm{~mm}, n_{\mathrm{D}}^{32} 1.4384$.

4-Ethyldecanol (VI). The lithum aluminum hydride reduction of 2-ethyldecanoic acid $(3.5 \mathrm{~g}, 0.0175$ mole) gave the corresponding alcohol, 2-ethyldecanol, bp $134 \sim 7^{\circ} \mathrm{C} / 10 \sim 11 \mathrm{~mm}, n_{\mathrm{D}}^{32} \mathrm{l} .4402$, yield $1.3 \mathrm{~g}(40 \%)$ ). 3,5-Dinitrobenzoate: mp $23 \sim 5^{\circ} \mathrm{C}$ (from ethanol). Anal. Found: $\mathrm{C}, 59.91 ; \mathrm{H}, 7.76 ; \mathrm{N}, 7.08$; Calcd. for $\mathrm{C}_{19} \mathrm{H}_{28} \mathrm{O}_{6} \mathrm{~N}_{2}: \mathrm{C}, 59.98 ; \mathrm{H}, 7.42 ; \mathrm{N}, 7.36 \%$. The melting point was not depressed on admixture with a specimen of the benzoate obtained from "b-peak substance." 